\title{
Anaphylaxis caused by latex surgical gloves immediately after starting surgery -A case report-
}

\author{
Min Jeong Lee ${ }^{1}$, Sang-Hwan $\mathrm{Do}^{2}$, Hyo-Seok Na², Mi-Hyun Kim², Young-Tae Jeon ${ }^{2}$, and Jung-Won Hwang \\ Department of Anesthesiology and Pain Medicine, ${ }^{1}$ Seoul National University Hospital, Seoul, ${ }^{2}$ Seoul National University Bundang \\ Hospital, Seongnam, Korea
}

Anaphylaxis is an acute and fatal systemic allergic reaction to an allergen, and it can be an unpredictable and lifethreatening cause during anesthesia. Latex is the second most common cause of anaphylaxis following the use of neuromuscular blocking agents during general anesthesia or surgery. We report on a 67-year-old male who had undergone surgery under general anesthesia without any problem but who presented with severe intraoperative anaphylaxis to latex surgical gloves. This case emphasizes the need for anesthesiologists to quickly diagnose and properly manage an allergic reaction in patients under general anesthesia. (Korean J Anesthesiol 2010; 59: S99-S102)

Key Words: Anaphylaxis, General anesthesia, Latex.

Anaphylaxis during anesthesia occurs infrequently but is known to cause death in approximately $0.65-2 \%$ of cases [1]. Furthermore, once anaphylaxis occurs, it is life-threatening, so the anesthesiologist must know how to manage it promptly and accurately. It is difficult to diagnose and find the cause for anaphylaxis after the induction of general anesthesia, because there are numerous types of drugs used during general anesthesia that can cause allergic reactions. Neuromuscular blocking agents are the most common cause of anaphylaxis in relation to anesthesia and surgery, and latex and antibiotics are the second and third common causes respectively [2].

In addition to the various goods used in our daily lives, such as sports items, gloves, balloons, and condoms, many medical products are made of latex. Therefore, there has been a growing occurrence rate of allergic reactions to latex during anesthesia and surgery $[3,4]$.

We experienced a sudden hemodynamic collapse due to an unknown cause immediately after starting surgery. After confirming that it was latex-triggered anaphylaxis, we report the case with literatures.

\section{Case Report}

A $178 \mathrm{~cm}, 64 \mathrm{~kg}$ and 67-year-old male patient, who suffered from continuous epigastric pain and nausea for about 1 month, was admitted. Stomach cancer was diagnosed from the endoscopic biopsy, so a total gastrectomy was decided. The patient had no past medical history other than an appen-

Received: May 28, 2010. Revised: 1st, June 7, 2010; 2nd, June 21, 2010. Accepted: June 28, 2010.

Corresponding author: Sang-Hwan Do, M.D., Department of Anesthesiology and Pain Medicine, Seoul National University Bundang Hospital, Gumi-dong, Bundang-gu, Seongnam 463-707, Korea. Tel: 82-31-787-7501, Fax: 82-31-787-4063, E-mail: shdo@snu.ac.kr

(c) This is an open-access article distributed under the terms of the Creative Commons Attribution Non-Commercial License (http:// creativecommons.org/licenses/by-nc/3.0/), which permits unrestricted non-commercial use, distribution, and reproduction in any medium, provided the original work is properly cited. 
dectomy.

To reduce the patient's anxiety, $2 \mathrm{mg}$ of midazolam was administered intravenously. Once arriving at the operating room, standard monitoring of electrocardiogram, pulse oximetry, and noninvasive blood pressure were established before the induction of anesthesia. The initial vital signs were arterial pressure of $123 / 71 \mathrm{mmHg}$, pulse rate of $73 \mathrm{rate} / \mathrm{min}$, and peripheral oxygen saturation $\left(\mathrm{SpO}_{2}\right)$ of $100 \%$. General anesthesia was induced with remifentanil and propofol at target effect-site concentrations of $3.0 \mathrm{ng} / \mathrm{ml}$ and $4.0 \mu \mathrm{g} / \mathrm{ml}$, respectively, using target-controlled infusion device (Orchestra ${ }^{\circledR}$ infusion pump system, Fresenius vial, Brezins, France), and $40 \mathrm{mg}$ of rocuronium was administered intravenously. After 2 min of manual ventilation, intubation was performed with a $7.5 \mathrm{~mm}$ diameter cuffed endotracheal tube. After tracheal intubation, mechanical ventilation was performed using oxygen and medical air $\left(\mathrm{FiO}_{2}=0.5\right)$ to make an end-tidal carbon dioxide level between 30 and $35 \mathrm{mmHg}$. Anesthesia was maintained by propofol and remifentanil infusion. A $16 \mathrm{Fr}$ Foley catheter was inserted and a nasopharyngeal thermometer was placed. Antibiotic drug, $1 \mathrm{~g}$ of cefazoline, was administered intravenously after the negative response was confirmed on an intradermal test.

Approximately 35 minutes after the induction of general anesthesia, the skin incision was started and $5 \mathrm{~min}$ later, the arterial pressure was suddenly dropped to $50 / 36 \mathrm{mmHg}, \mathrm{SpO}_{2}$ was reduced to $80 \%$, and the pulse rate was elevated above $120 \mathrm{rates} / \mathrm{min}$. The lungs were ventilated with oxygen $\left(\mathrm{FiO}_{2}\right.$ $=1.0$ ) and remifentanil infusion was stopped. Despite 10 mg ephedrine and $20 \mu \mathrm{g}$ phenylephrine were administered intravenously to raise the arterial pressure, there were no changes in the arterial pressure or heart rate. Rale and wheezing in both lungs were heard upon auscultation of the chest, thus airway secretions were removed by tracheal suction and salbutamol sulfate (Ventolin ${ }^{\mathrm{TM}}$ inhaler, $100 \mu \mathrm{g} /$ puff, GlaxoSmithKline, Madrid, Spain) was sprayed 2-3 times through the endotracheal tube. A 20 gauge catheter was placed on the right radial artery for continuous arterial pressure monitoring. An arterial blood gas analysis was performed, which showed pH 7.17, $\mathrm{PaCO}_{2} 60.6 \mathrm{mmHg}, \mathrm{PaO}_{2} 80.7 \mathrm{mmHg}, \mathrm{HCO}_{3}$ $21.5 \mathrm{mmHg}, \mathrm{SaO}_{2} 92.5 \%, \mathrm{Na}^{+} 154.2 \mathrm{mmol} / \mathrm{L}, \mathrm{K}^{+} 5.16 \mathrm{mmol} /$ $\mathrm{L}$, and $\mathrm{Ca}^{2+} 1.46 \mathrm{mmol} / \mathrm{L}$. In addition, $20 \mu \mathrm{g}$ phenylephrine was administered, and continuous infusion of $10 \mu \mathrm{g} / \mathrm{kg} / \mathrm{min}$ dopamine and $0.02 \mu \mathrm{g} / \mathrm{kg} / \mathrm{min}$ norepinephrine were started afterwards. Epinephrine (0.2 mg) was injected subcutaneously for bronchial dilation, and the broncho-tracheal suction and salbutamol sulfate treatment were performed repetitively. However the patient's hemodynamic vital signs did not improve, so a transesophageal echocardiogram was performed to evaluate cardiac function and to rule out thromoembolism.
However, there were no structural or functional specific findings, and a simple chest X-ray also did not result in any specific abnormal findings.

An arterial blood gas analysis was performed again $50 \mathrm{~min}$ after the surgery, when the $\mathrm{FiO}_{2}$ was at 1.0, which showed $\mathrm{pH}$ 7.18, $\mathrm{PaCO}_{2} 67.9 \mathrm{mmHg}$, and $\mathrm{PaO}_{2} 141.7 \mathrm{mmHg} . \mathrm{PaO}_{2}$ had improved, but $\mathrm{PaCO}_{2}$ was still high. Large amount of secretion in the airway was revealed by bronchoscopy. The surgery was at dissection of omentum before starting the main procedure of a total gastrectomy. Despite the various managements, systolic arterial pressure remained below $80 \mathrm{mmHg}$, and pulse rate remained continuously above 125 rates/min. So judging that proceeding with the surgery would be risky for the patient, it was determined that the surgery was terminated and the patient should be transferred to the intensive care unit (ICU). Total anesthesia time was $95 \mathrm{~min}$ and total surgery time was 60 min with infused crystalloid solution, infused colloid solution, estimated blood loss, and urine volume of 1,000 ml, $500 \mathrm{ml}, 100$ $\mathrm{ml}$ and $400 \mathrm{ml}$, respectively. While the patient was being moved to the ICU, skin rash and urticaria were discovered on his chest and abdomen. So $4 \mathrm{mg}$ of chlorpheniramine and $5 \mathrm{mg}$ of dexamethasone were administered immediately. Upon arriving in the ICU, the patient's vital signs were as follows; arterial pressure of $117 / 67 \mathrm{mmHg}$, pulse rate 127 rates/min, and $\mathrm{SpO}_{2}$ of $95 \%$. The patient's hemodynamic vital signs slowly stabilized and returned to the preoperative levels about $1 \mathrm{hr}$ after. Skin rash and urticaria disappeared and the endotracheal tube was removed after the consciousness was recovered. The next day the patient was transferred to the ward.

The sudden occurrence of cardiovascular collapse and the outbreak of rash and urticaria led us to suspect anaphylaxis. A skin test was decided upon to identify the drugs that could have been the cause. After two weeks, a skin test had been performed, which showed only a strong positive response to latex. A weak positive response appeared just on the intradermal test when $10 \mathrm{mg} / \mathrm{ml}$ rocuronium was tested. Other than that, there were no specific responses to intraoperatively used anesthetic or antibiotic drug administered immediately before surgery. When rocuronium was administered, hemodynamic stability was maintained until before starting the surgery, however, several minutes into the surgery, the patient became hemodynamically unstable. That led us to strongly suspect that the anaphylaxis had been caused by latex rather than by rocuronium.

One week later, a total gastrectomy was performed again. Thirty mg of methylprednisolone was administered twice at 12 $\mathrm{hr}$ and $2 \mathrm{hr}$ before surgery, and $4 \mathrm{mg}$ of chlorpheniramine and $50 \mathrm{mg}$ of ranitidine were administered $1 \mathrm{hr}$ before surgery. To prevent exposure of the patient to latex during the whole time of anesthesia and surgery, the surgical gloves (Biogel ${ }^{\circledR}$ Skinsense, Mölnlycke Health Care, Norcross, GA, USA) and all other items 
were prepared with latex-free products. There was no latex-free Foley catheter, so it was not inserted. As rocuronium had shown a weak positive response on the intradermal test, atracurium was used instead, which showed a negative response. Propofol, remifentanil, and atracurium were used for general anesthesia, and the surgery proceeded uneventfully. The patient was discharged 7 days later in better condition.

\section{Discussion}

Latex allergy was first reported by Nutter in 1979 [5]. With the increased use of products and medical supplies made of latex, the latex allergy has occurred more since then $[3,4]$. High risk factors leading to latex allergy are congenital abnormality in the urinary system, neural tube anomaly such as spinal bifida, occupational exposure, food allergies such as kiwis, avocados, nuts, and bananas, history of atopy, repeated surgeries or hand eczema, and so on. In patients with these risk factors, cross reaction to latex is more common and allergic reaction can be triggered frequently [6,7]. A latex allergy is caused from the direct contact to skin or mucosa, inhalation, ingestion, or parenteral injection.

The mechanism of latex allergic reactions can be classified into irritant contact dermatitis, type I hypersensitivity, and type IV hypersensitivity. Irritant contact dermatitis is most commonly found in people using latex products and it can be aggravated by soap or presurgical hand washing. It must be noted that irritant contact dermatitis is strictly not an allergy to latex, however allergic symptoms can be accelerated by the latex antigens absorbed through the skin [8]. In a type I hypersensitivity, allergic reaction is provoked by re-exposure to the previous sensitized antigen i.e. latex. Subsequently, sensitized mast cells and basophills by IgE emit histamines, leukotriene, and other inflammatory mediators. Skin reactions such as erythema or rash, upper airway symptoms, angiodema, and gastrointestinal symptoms may appear. In severe cases, anaphylactic responses can cause tachycardia, hypotension, hypoxia, and cardiovascular collapse $[9,10]$. Type IV hypersensitivity is a cell mediated immune response and occurred as contact dermatitis. In this case, skin reaction takes 6-72 hrs to develop after contact with the causative agent. Patients with type IV hypersensitivity do not show type I hypersensitivity, but $79 \%$ of patients with type I hypersensitivity also present type IV hypersensitivity $[9,10]$.

Patient's history must be taken in detail for a diagnosis of latex allergy, and skin prick tests, skin patch test, glove-use test, and serological test to identify latex-specific IgE can be performed in high-risk patients $[11,12]$. In addition, when skin rash, wheezing, or cardiovascular collapse occurs without any specific cause during the surgery, anaphylaxis by latex should be considered for a differential diagnosis.

Anaphylaxis during general anesthesia is caused primarily by neuromuscular blocking agents and secondly by latex [2]. Our patient showed a strong positive response to latex in a postoperative skin prick test. Rocuronium, the most common cause of anaphylaxis, was negative on a skin prick test, but a more sensitive intra-dermal test showed a weak positive response. Usually, anaphylactic responses occur within a few minutes after the exposure to an allergen. However, this patient showed no specific symptoms before beginning the operation, and he immediately presented severe hypotension, tachycardia, oxygen desaturation, and reduced end tidal $\mathrm{CO}_{2}$ as soon as surgery commenced. With a strong positive reaction to latex in skin prick test, latex of surgical gloves could be regarded as a cause of anaphylaxis. On the other hand, rocuronium showed a weak positive response on intra-dermal test and cardiovascular collapse occurred 35 minutes after the rocuronium administration, therefore it could not be considered as allergen. Although we did not measure IgE to the latex antigen, it was deduced that the anaphylaxis was caused by latex by observing the sudden clinical symptoms combined with skin rash as well as the skin tests performed afterwards.

In this case, pretreatment was undergone to reduce the allergic reaction on second operation, but it is controversial. Regardless of pretreatment, making sure that the patient is not exposed to latex is the most important factor. As the patient can be exposed to latex particles in the air, it is recommended to proceed first with elective surgeries. The operating room door should be clearly marked with a sign that says "latex allergy", and medical staff wearing or who have worn latex gloves should not be freely admitted [13]. This patient was continuously exposed to latex during the treatment was given for the sudden hemodynamic collapse, because dissection of omentum was being performed. Therefore, the administration of drugs to counter the cardiovascular symptoms did not produce a satisfactory response.

Symptoms of an anaphylactic response are typically related to cardiovascular collapse such as hypotension, tachycardia, and oxygen desaturation. However, these symptoms can commonly occur with other pathological conditions. Therefore, when cardiovascular collapse of an unknown cause occurs, a differential diagnosis of latex-caused anaphylaxis should be considered. Anaphylaxis occurs rarely, but once it occurs, it can bring on fatal effects regardless of the causative agent. When anaphylaxis is suspected during anesthesia, the anesthesiologist should remove all possible causative factors and take proper managements, such as ventilation with $100 \%$ oxygen, administration of epinephrine, antihistamines, and steroids, and so on. When the patient's stability is regained, the exact cause of anaphylaxis should be identified, and then a detailed 
medical record should be made. Latex allergy should be clearly explained to the patient and guardian so they can be certain to avoid latex exposure in the future.

Our patient did not have any specific risk factors and his medical history showed that he had an uneventful surgery for appendicitis many years before, so it was difficult to immediately diagnose that the anaphylaxis was caused by latex. Approximately $6-7 \%$ of patients, other than those suspected to belong to a high-risk group, are sensitized to latex [14]. Thus, careful and detailed history taking prior to surgery is needed. If a patient has a history of latex-caused anaphylaxis or has risk factors, then one should make sure not to expose the patient to latex when they are anesthetized.

\section{References}

1. Greenberger PA, Rotskoff BD, Lifschultz B. Fatal anaphylaxis: postmortem findings and associated comorbid diseases. Ann Allergy Asthma Immunol 2007; 98: 252-7.

2. Mertes PM, Laxenaire MC. Allergic reactions occurring during anaesthesia. Eur J Anaesthesiol 2002; 19: 240-62.

3. Vervloet D, Magnan A, Birnbaum J, Pradal M. Allergic emergencies seen in surgical suites. Clin Rev Allergy Immunol 1999; 17: 459-67.

4. Mertes PM, Laxenaire MC, Alla F. Anaphylactic and anaphylactoid reactions occurring during anesthesia in France in 1999-2000.
Anesthesiology 2003; 99: 536-45.

5. Nutter AF. Contact urticaria to rubber. Br J Dermatol 1979; 101: 597-8.

6. Taylor JS, Erkek E. Latex allergy: diagnosis and management. Dermatol Ther 2004; 17: 289-301.

7. Slater JE. Rubber anaphylaxis. N Engl J Med 1989; 320: 1126-30.

8. Del Savio B, Sheretz EF. Is allergic contact dermatitis being overlooked? Arch Fam Med 1994; 3: 537-43.

9. Heese A, Van Hintzenstern J, Peters KP, Koch HU, Hornstein OP. Allergic and irritant reactions to rubber gloves in medical health services. Spectrum, diagnostic approach and therapy. J Am Acad Dermatol 1991; 25: 831-9.

10. Charous BL, Hamilton RG, Yunginger JW. Occupational latex exposure: characteristics of contact and systemic reactions in 47 workers. J Allergy Clin Immunol 1994; 94: 12-8.

11. Buss ZS, Kulpek E, Fröde TS. Screening for latex sensitization by questionnaire: diagnostic performance in health care workers. J Investig Allergol Clin Immunol 2008; 18: 12-6.

12. Woods JA, Lambert S, Platts-Mills TA, Drake DB, Edlich RF. Natural rubber latex allergy: spectrum, diagnostic approach, and therapy. J Emerg Med 1997; 15: 71-85.

13. Holzman RS. Clinical management of latex-allergic children. Anesth Analg 1997; 85: 529-33.

14. Lebenbom-Mansour MH, Oesterle JR, Ownby DR, Jennett MK, Post SK, Zaglaniczy K. The incidence of latex sensitivity in ambulatory surgical patients: a correlation of historical factors with positive serum immunoglobin E levels. Anesth Analg 1997; 85: 44-9. 